\title{
Sorption of Nitrogen and Water Vapor on Textile Fibers
}

\author{
By John W. Rowen and R. L. Blaine
}

\begin{abstract}
Measurements were made of the adsorption of nitrogen and water vapor on six purified textile fibers and titanium dioxide. It was found that all of the fibers had a relatively low capacity for the adsorption of nitrogen as compared with the capacity for the adsorption of water vapor. The surface area values ranged from 0.31 square meter per gram for nylon to 0.98 square meter per gram for viscose rayon. The values of the free surface energies of adsorption as ealculated by the Gibbs adsorption equation were the same for wool, cotton, silk, and rayon fibers but differed for the two synthetic polymers, nylon and acetate rayon.
\end{abstract}

\section{Introduction}

There is evidence that surface characteristics of textile fibers have some effect on the properties of the finished-textile fabrics. Examples of such evidence of surface properties are apparent in the phenomenon of water-repellency $[1,2],{ }^{2}$ in the loss of light-reflectance [3] and in the difference in moisture-sorption capacities of fabrics $[4,5]$ after various treatments. Although the importance of surface characteristics and properties has long been recognized in the technology of colloids and other sciences, the relation of these surface properties to the properties of fabrics is not well understood.

Several workers $[6,7,8,9,10,11,12]$ have interpreted the adsorption of water by some textile materials (such as cellulose, wool, nylon, etc.) as a phenomenon in multimolecular [13] adsorption. If one assumes that the adsorption is a multilayer phenomenon, one may calculate that the surface area accessible to the first layer is in the range from 100 to $200 \mathrm{~m}^{2} / \mathrm{g}$. This range of values is several orders of magnitude greater than the value $\left(0.60 \mathrm{~m}^{2} / \mathrm{g}\right)$ calculated by Emmett and DeWitt [14] from nitrogen adsorption measurements on paper cellulose. On the other hand, this range of values is not appreciably greater than the value $\left(53.0 \mathrm{~m}^{2} / \mathrm{g}\right)$ reported by Purves [9] et al., working with nitrogen on a swollen cotton cellulose.

In order to obtain reliable surface area measurements of textile materials it is necessary to measure the surface area under conditions en-

\footnotetext{
1 This paper will also appear in the December 1947 issue of the J. Ind. and Eng. Chem.

${ }^{2}$ Figures in brackets indicate the literature references at the end of this paper.
}

suring true physical adsorption. Brunauer, Emmett, and Teller [13] and Harkins and Jura [15] have shown that the adsorption isotherms of nitrogen, at $-195^{\circ} \mathrm{C}$ (the boiling point of nitrogen, at which temperature nitrogen is physically adsorbed on solids) may be used to calculate the true surface areas of a great many crystalline and amorphous materials.

Knowledge of the molecular area or surface area [16] is believed necessary in order to evaluate such properties as the free surface energy [17] of adsorption and the work of adhesion [18] between the liquid and the solid phase. It therefore seemed highly desirable that the surface areas of the more common textile fibers - cotton, wool, viscose, silk, nylon, and cellulose acetate-be measured. It also seemed desirable to obtain the water adsorption isotherms of the same samples used in the nitrogen adsorption experiments. The work presented in the paper represents a portion of the preliminary work of a larger program sponsored and supported by the Office of the Quartermaster General, War Department. ${ }^{3}$ It is intended to provide comparative data on the adsorption of the two vapors on six different purified textile materials.

\section{Materials and Their Preparation}

Six purified textile fibers and a sample of titanium dioxide (anatase) were used in this study. The four fibers, cotton, wool, silk, and rayon are from the samples studied by Wiegerink [19]. The titanium dioxide was employed as a reference standard. The cotton was purified by extracting

${ }^{3}$ Permission to publish this paper was granted by the Office of the Quartermaster General. 
with alcohol for 8 hours and with ether for 8 hours, followed by four washings in distilled water at $50^{\circ}$ to $60^{\circ} \mathrm{C}$. The wool was also extracted with ether and alcohol until the extracting liquid was free of residue traces. The wool was then washed at $50^{\circ}$ to $60^{\circ} \mathrm{C}$ in distilled water. The raw silk was degummed in soap solution and then extracted with alcohol and ether. It was then thoroughly washed in distilled water. The viscose rayon was washed four times in a 1-percent water solution of ammonia at $50^{\circ}$ to $60^{\circ} \mathrm{C}$ and then washed four times with distilled water at the same temperature.

The sample of nylon used in this study was 40 denier, 13 filament yarn, having one-half turn per inch of $Z$ twist. The sample was supplied by the E. I. duPont de Nemours Co. It was extracted for 6 hours with ethyl ether. This length of time proved sufficient for the complete removal of the 0.4 percent of oil base lubricant applied during spinning. The acetate rayon was 150 denier, 46 filament yarn having $2 \frac{1}{2}$ turns per inch and was supplied by the American Viscose Co. The sample was washed four times in distilled water at $50^{\circ}$ and $60^{\circ} \mathrm{C}$.

\section{Test Methods}

The sorption of water by the textiles was determined gravimetrically using an analytical balance in conjunction with the conditioning apparatus described by Carson and Worthington [20]. In this apparatus the partial pressure of the water is maintained by means of saturated salt solutions, and the samples may be weighed without removal from the conditioned atmosphere. The moisture vapor pressures were obtained from wet and dry bulb temperatures and also by means of a Dunmore [21] electric hygrometer. The dry weights of the 5-gram samples of yarn were obtained by placing them over phosphorous pentoxide until constant weight was obtained. This constant weight was attained in about 5 days. It was observed that no loss of weight occurred from the fifth to the thirtieth day. After this drying period, the fibers were in equilibrium with an atmosphere whose relative water vapor partial pressure was less than 0.01. After the dry equilibrium point had been attained, the moisture content of the sample was determined at a series of increasing relative water vapor pressures. The rate of change of weight was plotted against time at each partial pressure, and the equilibrium value, usually attained within 24 to 48 hours, was indicated by the rate curve.

The adsorption of nitrogen was determined by a method similar to the one used by Brunauer and Emmett [22]. The saturation vapor pressure of the nitrogen was determined by use of a vapor pressure thermometer using the purified gas employed for the adsorption experiment.

The low temperature adsorption tests were made on 20- to 50-gram samples of the fibers. The sample bulb was packed as tightly as possible for each determination to reduce the dead space correction. For the experiments reported in this article, the textile fibers were evacuated for 16 to 20 hours at room temperature (about $25^{\circ} \mathrm{C}$ ) to a pressure of about $10^{-6} \mathrm{~mm}$ of $\mathrm{Hg}$. Other preliminary tests were made in which the temperature of evacuation was higher and one experiment was made of the cotton-fiber surface available to oxygen. For the low temperature adsorption of $\mathrm{TiO}_{2}$, the temperature of evacuation was $200^{\circ} \mathrm{C}$. Helium was used in evaluating the dead space in the sample bulb.

\section{Results and Discussion}

\section{Adsorption Measurements}

As shown in figures 1, 2, and 3, the adsorption isotherms of both water vapor and nitrogen were found to be sigmoid-shaped, corresponding to the type II of the five types classified by Brunauer [23]. This type of adsorption curve is characteristic of physical adsorption on rigid solids with pore diameters larger than the molecular diameters of the adsorbed molecules [24]. However, this type of adsorption curve also occurs with nonrigid solids in which the adsorption sites are not restricted to the surface.

It may be noted from figure 1 that the milimoles of water vapor and nitrogen adsorbed by the $\mathrm{TiO}_{2}$ differ only by a small percentage [25]. This is true despite the fact that the nitrogen was adsorbed after thorough evacuation, whereas water vapor was adsorbed from mixtures in air after drying the sample over $\mathrm{P}_{2} \mathrm{O}_{5}$. On the other hand, comparing the adsorption isotherms of the textile fibers in figures 2 and 3 , and the data in table 1 reveals that the order of magnitude of adsorption capacity of nitrogen and water vapor are not the 


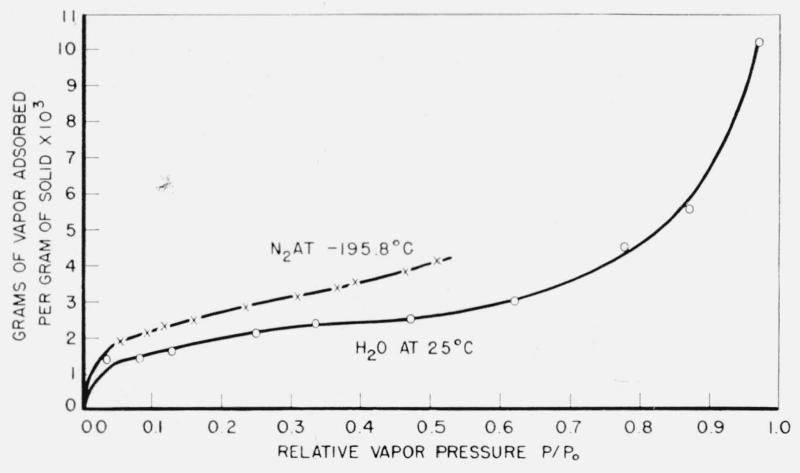

FIGURE 1.-Adsorption isotherms of water and nitrogen on titanium dioxide.

same. All the fibers had relatively low capacity for the adsorption of nitrogen as compared with the relatively high capacity for adsorption of water vapor.

The wool and viscose rayon fibers had slightly greater nitrogen adsorption capacities than silk and cotton, and the adsorption capacities of the acetate and nylon fibers were the lowest. In the adsorption of water vapor, the wool and viscose rayon fibers also had greater adsorption capacity

TABLE 1.- Sorption of nitrogen and water vapors on textile fibers

\begin{tabular}{|c|c|c|c|c|c|c|}
\hline \multicolumn{7}{|c|}{ MILLIMOLES OF WATER VAPOR (PER GRAM OF SOLID) } \\
\hline$P / P_{0}$ & Wool & $\begin{array}{l}\text { Viscose } \\
\text { rayon }\end{array}$ & Silk & Cotton & Acetate & Nylon \\
\hline 0.034 & 1.3 & 1. 2 & 0.7 & 0.7 & ..... & 0.2 \\
\hline .081 & 1.9 & 1.8 & 1.1 & 1.1 & ..... & .4 \\
\hline .130 & 2.3 & 2.1 & 1.4 & 1. 3 & 0.8 & .6 \\
\hline .252 & 3. 6 & 3.2 & 2.3 & 1.9 & 1.3 & 1.0 \\
\hline .335 & 4. 6 & 4.0 & 2. 9 & 2.4 & 1. 7 & 1.3 \\
\hline .471 & 5.7 & 4.8 & 3. 6 & 2.9 & 2.3 & 1.7 \\
\hline .620 & 7.1 & 6.2 & 4. 6 & 3.7 & 3. 2 & 2.1 \\
\hline .778 & 9.5 & 8.4 & 6.4 & 5.4 & 4.8 & 2.9 \\
\hline .866 & 11. 6 & 10.8 & 8.3 & 6.4 & 6.0 & 3.5 . \\
\hline .968 & 14.4 & 14.5 & 11.5 & 8.2 & 7.5 & 4.2 \\
\hline \multicolumn{7}{|c|}{$\begin{array}{l}\text { MILLIMOLES OF NITROGEN VAPOR } \times 10^{2} \text { (PER GRAM OF } \\
\text { SOLID) }\end{array}$} \\
\hline 0.05 & 1.1 & 1.4 & 0.7 & 0.8 & 0.3 & 0.3 \\
\hline .10 & 1.4 & 1. 7 & 1. 1 & 1.1 & .4 & .4 \\
\hline .15 & 1.7 & 2.0 & 1. 4 & 1.3 & .5 & .5 \\
\hline .20 & 1.9 & 2.2 & 1. 7 & 1.6 & .6 & .6 \\
\hline .25 & 2.2 & 2.5 & 2. 0 & 1.8 & .7 & .7 \\
\hline .30 & 2.4 & 2.7 & 2. 3 & 2.0 & .8 & .8 \\
\hline .35 & 2.7 & 2.9 & 2. 7 & 2.3 & .9 & .9 \\
\hline .40 & 2.9 & -..... & 2. 9 & 2.6 & 1.1 & 1.1 \\
\hline .45 & 3.1 & ...... & 3. 6 & ..... & 1. 3 & 1. 3 \\
\hline .50 & 3.4 & .... & 4. 1 & ..... & 1.4 & 1. 4 \\
\hline .55 & 3.8 & -.... & 4. 6 & - . . & 1. 7 & 1. 7 \\
\hline
\end{tabular}

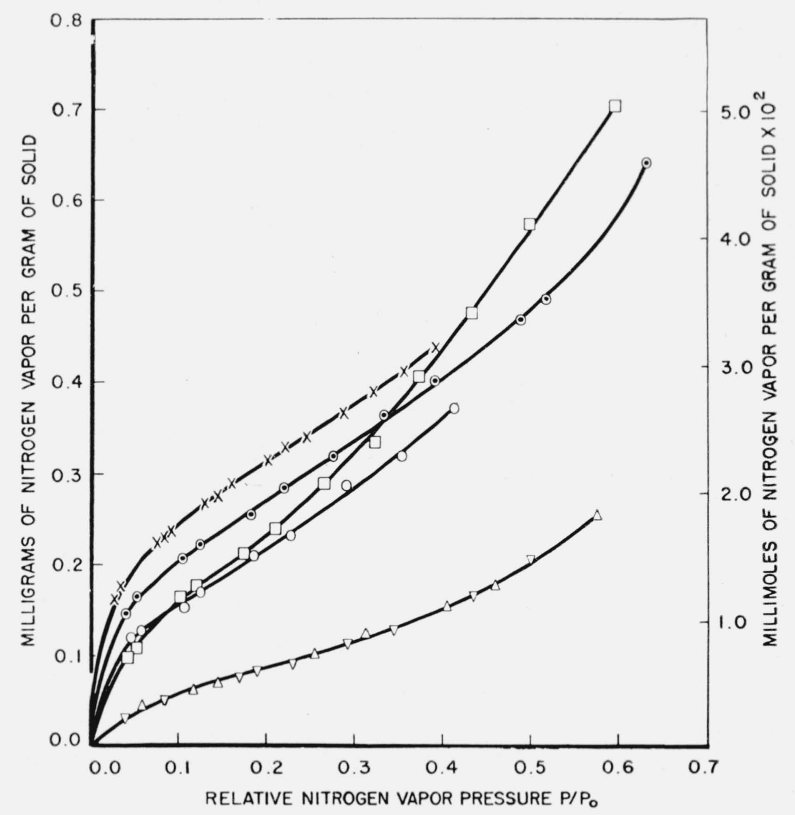

Figure 2.-Adsorption isotherms of nitrogen on six textile fibers at $-195^{\circ} \mathrm{C}$.

$\odot$, Wool; $X$, viscose; $\square$, silk; $\bigcirc$, cotton; $\nabla$, acetate; $\triangle$, nylon.

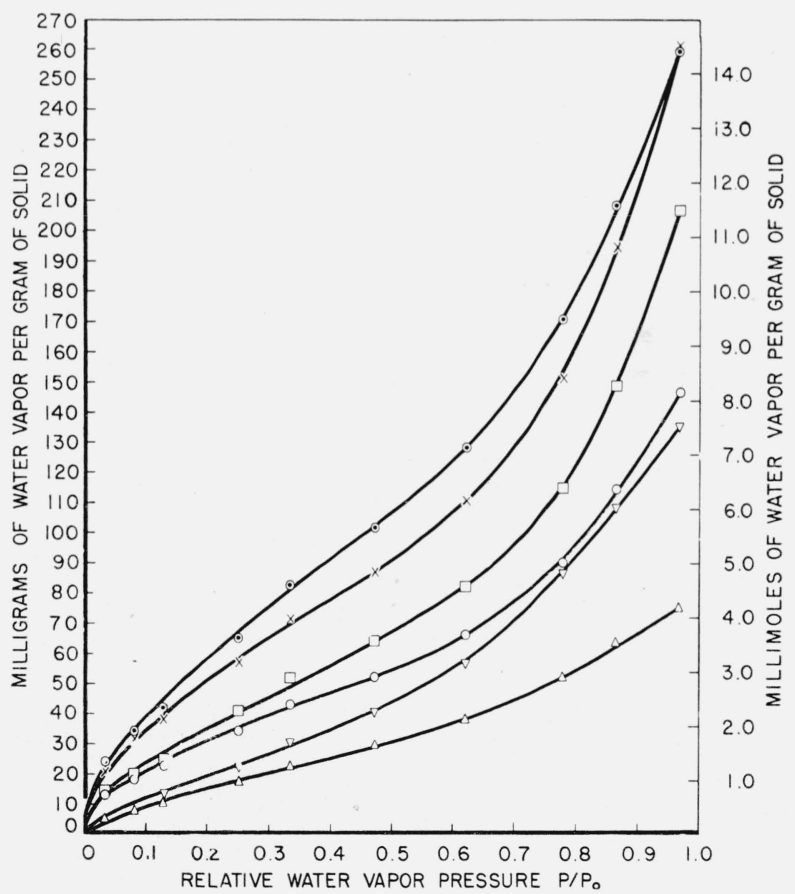

FIGURE 3.-Adsorption isotherms of water on six textile fibers at $25^{\circ} \mathrm{C}$.

$\odot$, Wool; X, viscose; $\square$, silk; $C$, cotton; $\nabla$, acetate; $\triangle$, nylon. 
than silk and cotton, whereas the acetate and nylon also had the lowest capacities. There was, however, a certain lack of parallelism and shifting of relative position. Sufficient study has not been made to indicate the significance of these differences.

\section{Calculated Quantities}

\section{(a) Surface Areas}

The surface areas of the fibers available to the nitrogen vapor were calculated according to the BET equation [26], now commonly used for calculating the surface areas of solid materials. In evaluating the quantities of gas required for a monolayer on each of the textile fibers, the customary method of plotting $P / V\left(P_{0}-P\right)$ versus $P / P_{0}$ was employed [26]. The plot is presented in figure 4 . The calculated surface area values are presented in table 2. All of the surface areas
TABLE 2.-Surface areas of textile fibers

\begin{tabular}{|c|c|}
\hline Material & $\begin{array}{c}\text { Area available } \\
\text { to nitrogen } \\
\text { molecule at } \\
-195^{\circ} \mathrm{C}\left(\mathrm{m}^{2} / \mathrm{g}\right)\end{array}$ \\
\hline Wool & 0.96 \\
\hline Viscose rayon & .98 \\
\hline Silk & .76 \\
\hline Cotton & .72 \\
\hline A cetate rayon & .38 \\
\hline Nylon . . . & .31 \\
\hline Titanium dioxide $\left(\mathrm{TiO}_{2}\right)$ & 7. 90 \\
\hline
\end{tabular}

Purves' experimental value suggests. The surface area of cotton cellulose thus appears to vary from at least 0.60 to $53.0 \mathrm{~m}^{2} / \mathrm{g}$, depending upon its history. The value for cellulose of $0.60 \mathrm{~m}^{2} / \mathrm{g}$ is only slightly larger than values $\left(0.1-0.3 \mathrm{~m}^{2} / \mathrm{g}\right)$ obtained by estimation of areas observed with the microscope and reported by

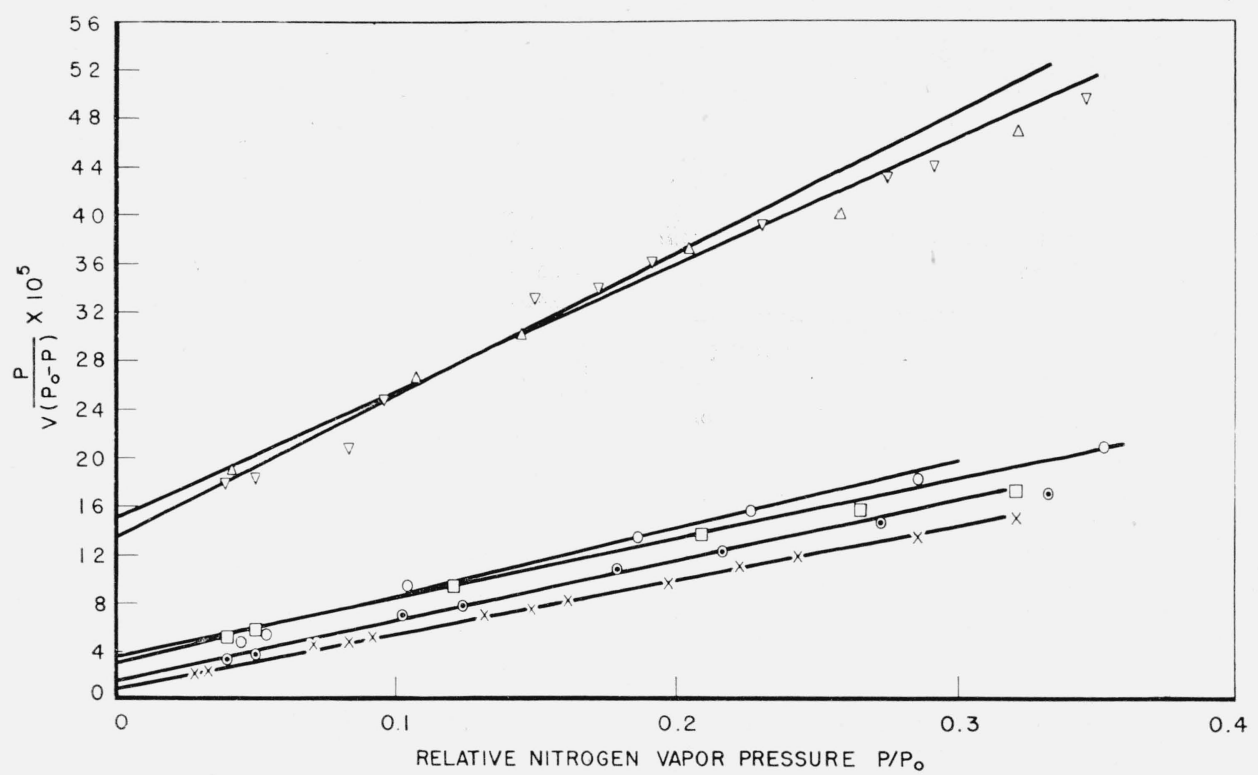

FIGURE 4.-BET plots used for obtaining surface areas accessible to nitrogen.

$\odot$, Wool; X, viscose; $\square$, silk; $O$, cotton; $\nabla$, acetate; $\triangle$, nylon.

were less than $1 \mathrm{~m}^{2} / \mathrm{g}$. The value obtained for cotton cellulose- $0.72 \mathrm{~m}^{2} / \mathrm{g}$ - compares favorably with the $0.60 \mathrm{~m}^{2} / \mathrm{g}$ value reported by Emmett and DeWitt [14]. However, it differs markedly from the value of 53.0 [9] reported by Purves for a sample of swollen cotton cellulose. It is pointed out that the surface area available to the nitrogen vapor may be greatly dependent upon the source and treatment as the comparison with
Stamm and Millett [6] and Howell and Jackson [27]. It is likely, therefore, that the surface area, as determined with nitrogen, represents a lower limit.

In view of the large differences between the adsorption capacities observed in the water isotherm and the nitrogen isotherm, it was of interest to calculate the "water" areas of the same samples. This calculation was carried out 
even though the authors were aware of the possibility that the data could be interpreted from another point of view. The plot of $P / V\left(P_{0}-P\right)$ versus $P / P_{0}$ is shown in figure 5 , and the areas that may be calculated from them, by assuming all adsorbing sites were on a free surface, are tabulated in table 3 . It may be noted in this table that the calculated surface areas of the

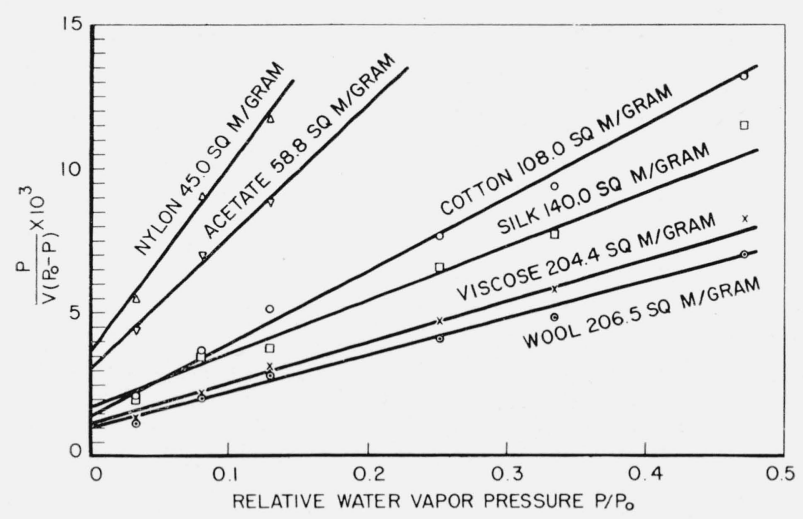

Figure 5.-BET plots used for obtaining surface areas accessible to water vapor.

textile fibers were from 150 to 200 times as great when determined by water adsorption as they were when determined by nitrogen adsorption.

TABLE 3.-Calculated surface areas accessible to water vapor and nitrogen vapor

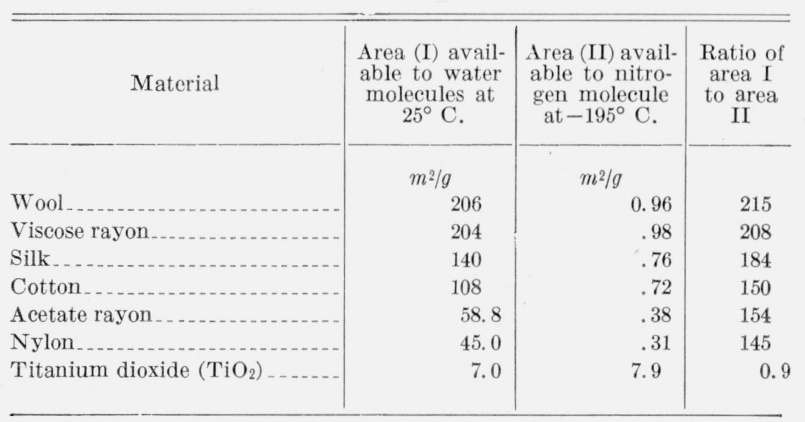

This apparent discrepancy may be explained in a number of ways:

1. The sites that adsorb water are not restricted to a free surface.

2. If the water allsorbing sites are restricted to a surface, there may be an additional internal surface specific to certain adsorbates as well as an external surface.

3. The internal surface within the fibrous struc- ture exists only in the presence of a swelling agent such as water.

4. The smaller diameter and the polarity of the water molecule enables it to penetrate into capillaries not accessible to the nitrogen molecule.

Stamm and Millett [6], after a careful consideration of various adsorption data on cellulose (including selective adsorption from solution and heats of swelling) concluded that all the estimated values in the literature for the surface areas of cellulose fell into two groups. The first group was about $0.2 \mathrm{~m}^{2} / \mathrm{g}$ - "the microscopically visible surface" - and the other group was about 300 $\mathrm{m}^{2} / \mathrm{g}$ - "the surface of the transient capillary structure created within the cell walls by the swelling agents".

It is pointed out by the present authors that all four of the above factors may operate to account for the apparent discrepancy. There is insufficient evidence at present for evaluating the relative merit of the four hypotheses suggested above.

Plotting the nitrogen and water vapor adsorption data according to the method suggested by Harkins and Jura [28] resulted in a line or series of lines concave to the $X$ axis rather than convex as usually found for other materials. In the two instances somewhat lower surface area values were obtained using this method of plotting.

\section{(b) Free Energy of Adsorption}

In view of the possibility that we are here dealing with an internal as well as an external surface, it seemed of interest to attempt to treat both systems as heterogeneous systems and to apply the relationship of J. Willard Gibbs [29]. This equation is applicable to interfaces between solid surfaces and vapors; it was written by Gibbs as follows:

Where:

$$
\sigma=\epsilon_{s}-t n_{s}-\mu_{1} \Gamma_{1}-\mu_{2} \Gamma_{2} .
$$

$\sigma=$ the work spent in forming a square centimeter of clean new surface,

$\boldsymbol{\epsilon}_{s}=$ surface total energy,

$t=$ temperature

$n=$ surface entropy,

$\mu_{1}=$ chemical potential of the solid at boundary,

$\mu_{2}=$ chemical potential of the vapor at boundary, 
$\Gamma_{1}=$ surface concentration of the solid, and

$\Gamma_{2}=$ surface concentration of the vapor.

Under isothermal conditions [30] and under conditions in which $\Gamma_{1}$ is set at zero (by choosing the Gibbs boundary so that the surface concentration of the solid is zero) eq (1) reduces to:

$$
d \sigma=-\Gamma_{2} d \mu_{2} .
$$

Under appropriate conditions $d \mu_{2}$ may be replaced by its equivalent $d(R T \ln P)$ where $P$ is the vapor pressure, and we have:

or

$$
d \sigma / d(R T \ln P)=-\Gamma_{2},
$$

and

$$
\int_{0}^{\sigma} d \sigma=R T \int_{0}^{P} \Gamma_{2} d \ln P,
$$

$$
\int_{0}^{\sigma} d \sigma=R T / M S \int_{0}^{P} q d \ln P .
$$

Where Gibbs' surface concentration $\Gamma_{2}$ is expressed $[32,33]$ as the number of moles of vapor adsorbed per square centimeter:

$$
\Gamma_{2}=q / M S \text {. }
$$

$q=$ grams of absorbate,

$M=$ its molecular weight, and

$S=$ total surface area

As $\sigma$ is the work required to form a square centimeter of surface, it is also the free surface energy, therefore, covering the surface with a vapor lowers the value of $\sigma$. This change of the free surface energy, which accompanies adsorption is referred to here as the free energy change of adsorption and designated $\Delta F$ as follows:

$$
\Delta F=R T / M S \int_{0}^{p} q / p d p
$$

The $\Delta F$ of eq (7) may be evaluated after experimental determination of $S, q$ and $P$. The integral $\int q / p d p$ can be obtained by graphical integration. This is done by estimating the area under the curve that is obtained when one plots values of $q / p$ vs $P$. Plots of the data of figures 2 and 3 in this manner are shown in figures 6 and 7. (See also [8]). As the plots do not lend themselves easily to extrapolation, the method used by Boyd and Livingston [32] was employed in obtaining the areas. The $\Delta F$ values thus ob-

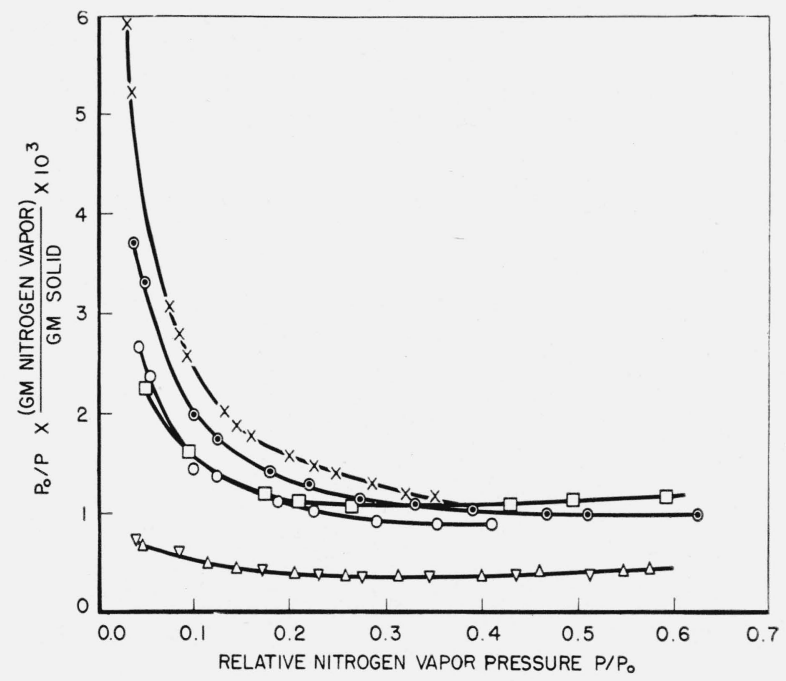

FIGURE 6.-Plot of nitrogen adsorption data in accordance with a modified Gibbs equation.

$\odot$, Wool; $\times$, viscose; $\square$, silk; $\bigcirc$, cotton; $\nabla$, acetate; $\triangle$, nylon.

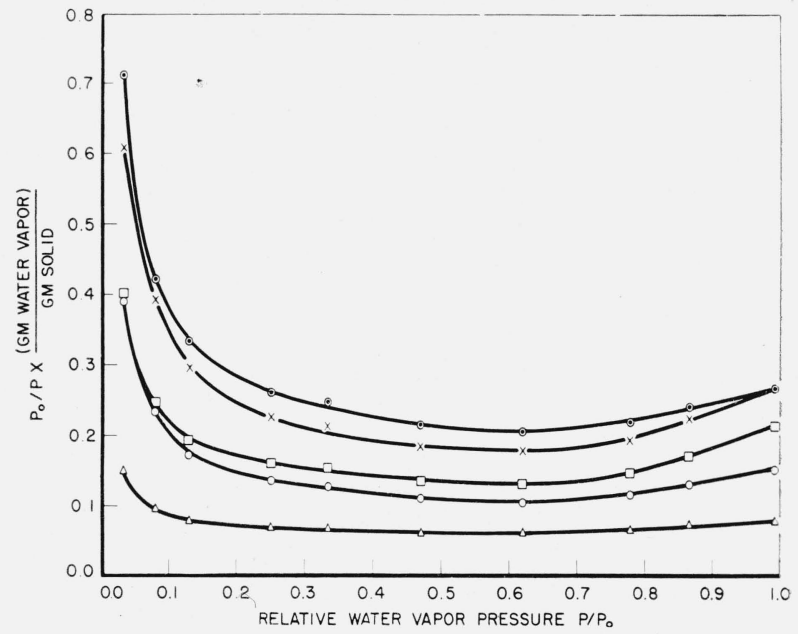

Figure 7.- Plot of water adsorption data in accordance with a modified Gibbs equation.

$\odot$, Wool; $X$, viscose; $\square$, silk; $\bigcirc$, cotton; $\triangle$, nylon.

tained were in turn plotted against the relative vapor pressure, $P / P_{0}$, and the resulting curres are shown in figure 8.

It is noted that the free energy of adsorption of water is the same at all relative vapor pressures for wool, silk, viscose, and cotton. The free energies of the two synthetic polymers, nylon, and acetate, did not fall on the common curve. As was the case in the surface area measurements, the free energy of adsorption of these two fibers was in a separate class (see table 4 ). With the 


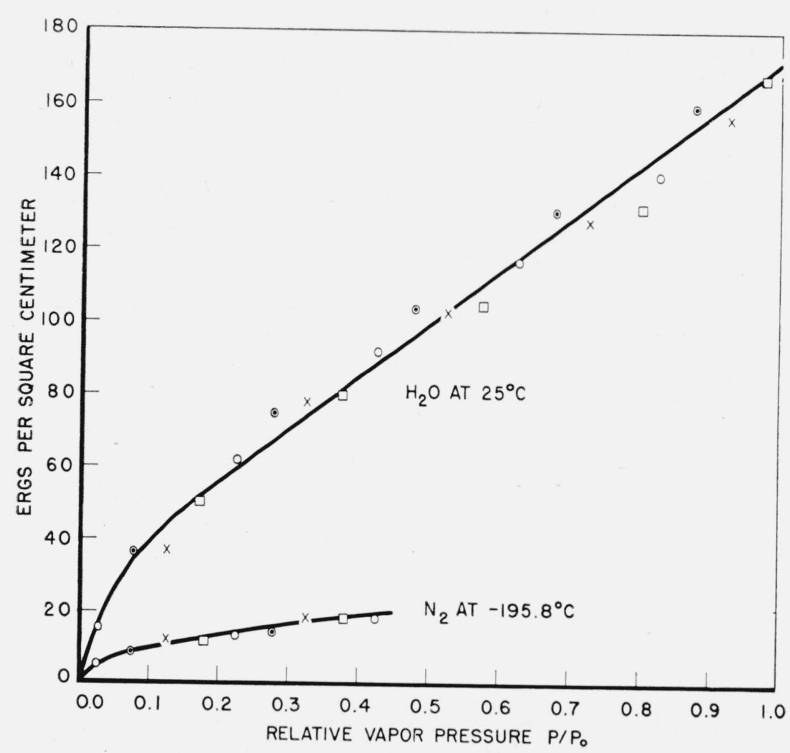

FIGURE 8.-- Free surface energy of adsorption as a function of relative vapor pressure.

$\odot$, Wool; $\times$, viscose; $\square$, silk; $\bigcirc$, cotton.

exception of nylon and cellulose acetate, whose fiber-water contact angles are greater than zero, the free energy of adsorption appears to be insensitive to the chemical nature of the adsorbent. It is possible that the bonding between the water and the four fibrous materials may be a hydrogen bond type. If such bonds existed in the four cases, the average value of a variety of hydrogen bond energies might very well be the same for the four materials.

TABLE 4.-Free energy of adsor ption of water and nitrogen on textile polymeric materials

\begin{tabular}{|c|c|c|c|c|}
\hline \multirow{2}{*}{ Material } & \multicolumn{2}{|c|}{ Water } & \multicolumn{2}{|c|}{ Nitrogen } \\
\hline & $P / P_{0}=0.40$ & $P / P_{0}=1.0$ & $P / P_{0}=0.40$ & $P / P_{0}=1.0$ \\
\hline & $\mathrm{e} / \mathrm{cm}^{2}$ & $\mathrm{e} / \mathrm{cm}^{2}$ & $\mathrm{e} / \mathrm{cm} m^{2}$ & $\mathrm{e} / \mathrm{cm}^{2}$ \\
\hline Wool & 89 & 170 & 20 & \\
\hline Viscose rayon & 89 & 170 & 20 & \\
\hline Silk__-_._- & 89 & 170 & 20 & \\
\hline Cotton & 89 & 170 & 20 & \\
\hline A cetate rayon.... & 114 & 247 & 14 & \\
\hline Nylon & 113 & 223 & 12 & \\
\hline
\end{tabular}

\section{Summary}

1. The sorption isotherms of water and nitrogen on six important textile materials have been determined.

2. The fiber surface areas available to the nitrogen have been computed with the aid of the theory of multilayer adsorption. The surface areas of the textile fibers were found to vary between 0.31 and $0.96 \mathrm{~m}^{2} / \mathrm{g}$. These values are of the same order of magnitude as the reported areas estimated with the aid of the microscope.

3 . The water and nitrogen isotherms on samples of the same textile fibers showed marked differences in sorptive capacities.

4. The free energy of adsorption of nitrogen on the six fibrous materials have been calculated.

5. The implications of these calculations are discussed.

Acknowledgment is made for some of the laboratory measurements made by Lee A. Dunlap and H. J. Valis.

\section{References}

[1] S. Baxter and A. B. D. Cassie, J. Textile Inst. 36, 167 (1945).

[2] J. W. Rowen and D. Gagliardi, J. Research NBS 38, 103 (1947). RP1762

[3] J. G. Wiegerink, J. Research NBS 25, 435 (1940). RP1337.

[4] J. W. McBain, The sorption of gases and vapours by solids, (George Routledge \& Sons, London, 1932).

[5] M. Harris, J. Research NBS 12, 475 (1934) RP673; 23, 299, (1939). RP1234

[6] A. J. Stamm and M. A. Millet, J. Phys. Chem. 45, 43 (1941).

[7] J. D. Babbitt; Can. J. Research 20, 143 (1942).

[8] H. B. Bull; J. Am. Chem. Soc. 66, 1499 (1944).

[9] A. C. Assaf, P. H. Haas, and C. B. Purves, J. Am. Chem. Soc. 66, 66 (1944).

[10] T. M. Shaw, J. Chem. Phys. 12, 391 (1944).

[11] L. Pauling, J. Am. Chem. Soc. 67, 555 (1945).

[12] G. Pickett, J. Am. Chem. Soc. 67, 1958 (1945).

[13] S. Brunauer, P. H. Emmett, and E. Tellor, J. Am. Chem. Soc. 60, 309 (1938).

[14] P. H. Emmett and T. DeWitt, Ind. \& Eng. Chem. Anal. Ed. 13, No. 1, 28 (1941).

[15] W. D. Harkins and G. Jura, J. Am. Chem. Soc. 66, 1366 (1944).

[16] G. E. Boyd, Surface chemistry, AAAS publication No. 21, 55 (Science Press Printing Co. 1943).

[17] D. H. Bangham, Trans. Farad. Soc. 33, part 1 and part 2 (1937).

[18] W. D. Harkins; Surface chemistry, AAAS publication No. 21, 55 (Science Press Printing Co. 1943).

[19] J. G. Wiegerink; J. Research NBS 24, 645 (1940). RP1304

[20] NBS Circular C 453 (1946).

[21] Bulletin 2140, American Instrument Co., Silver Spring, Md. (April 1946). 
[22] P. H. Emmett, A new method for measuring the surface areas of finely divided materials and for determining the size of particles. Symposium on New Methods for Particle Size Determination in the Subsieve Range, ASTM (1941).

[23] S. Brunauer, The adsorption of gases and vapors, p. 149 (Princeton Univ. Press, Princeton, N. J., 1943). Symposium on New Methods for Particle Size Determination in the Subsieve Range, ASTM (1941).

[24] P. H. Emmett and M. Cines, J. Am. Chem. Soc. 68, 2535 (1946).

[25] P. H. Emmett, J. Am. Chem. Soc. 68, 1784 (1946).

[26] S. Brunauer, The adsorption of gases and vapors (Princeton Univ. Press, Princeton, N. J., 1943).
[27] R. Howell and A. Jackson, J. Chem. Soc. (London) 979 (1937).

[28] W. D. Harkins and G. Jura, J. Am. Chem. Soc. 66, 1366 (1944).

[29] J. W. Gibbs, Collected works 1, 92 and 315 (Longmans, Green and Co., New York, N. Y. 1928).

[30] D. H. Bangham, Trans. Farad. Soc. 33, part 1 (1937).

[31] D. H. Bangham and R. K. Razouk, Trans. Farad. Soc. 33, part 2, 1463 (1937).

[32] G. E. Boyd and H. K. Livingston, J. Am. Chem. Soc. 64, 2383 (1942).

Washington, June 17, 1947. 